\title{
Enzymatic analysis of the effect of naturally occurring Leu138Pro mutation identified in SHV $\beta$-lactamase on hydrolysis of penicillin and ampicillin
}

Nabin Rayamajhi ${ }^{1}$, Jeong Chan Joo ${ }^{2}$, Seung Bin Cha ${ }^{1}$, Subarna Pokherl ${ }^{2}$, Min Kyung Shin ${ }^{1}$, Young Je Yoo ${ }^{2}$, Han Sang Yoo ${ }^{1 *}$

\begin{abstract}
Background: The aim of this study was to analyze the significance of leucine to proline substitution at position 138(Leu138Pro) on the hydrolysis of penicillin and ampicillin that we identified in the bla SHV $_{\text {gene of clinical }}$ Escherichia coli swine isolate.

Results: Kinetic analysis of the mutant proteins showed that $K_{m}$ value of the purified L138P mutant was comparatively higher than SHV-1, SHV-33 and SHV-33(L138P) enzyme for penicillin and ampicillin. Docking simulation of the SHV-1 and SHV-(L138P) enzymes also confirmed that $\beta$-lactamases preferred penicillin to ampicillin and the SHV-1 had a higher binding affinity for antibiotics compared to the SHV-(L138P) and other mutants.

Conclusions: Our result demonstrated that L138P has a reduced role in penicillin and ampicillin hydrolyzing properties of SHV $\beta$-lactamases. These naturally occurring mutations rendering reduced function of the existing protein could trigger the emergence or acquisition of more effective alternative mechanisms for $\beta$-lactam hydrolysis.
\end{abstract}

\section{Background}

Antimicrobial resistance based on hydrolysis of the antibiotic by $\beta$-lactamases is currently a worldwide problem. It is one of the single most prevalent mechanisms responsible for resistance to $\beta$-lactams in clinical isolates of the Enterobacteriaceae [1-3]. Among the four classes (A to D) of $\beta$-lactamases, plasmid mediated class $\mathrm{A}$ and $C \beta$-lactamases have been of high clinical concern in hospital as well as community acquired infections $[1,4]$. Promiscuous plasmids carrying $\beta$-lactamase encoding genes are described to spread drug resistance among different groups of microbes under local selection pressure imposed by the commonly used antibiotics $[1,5,3]$. One of the most common plasmid mediated

\footnotetext{
* Correspondence: yoohs@snu.ac.kr

'Department of Infectious Diseases, College of Veterinary Medicine, KRF Zoonotic Disease Priority Research Institute, Brain Korea 21 for Veterinary Science, Seoul National University, Seoul 151-742, S. Korea Full list of author information is available at the end of the article
}

$\beta$-lactamase enzymes is closely related to TEM and SHV penicillinase [6,3]. Recently CTX-M and AmpC type $\beta$-lactamase are being widely reported from Enterobacteriaceae that are associated with nosocomial and community acquired infections $[1,7]$.

Use of extended-spectrum $\beta$-lactam antibiotics has led to the occurrence of variants of these $\beta$-lactamases carrying amino acid substitutions that alter the enzyme's substrate specificity $[1,6,8,9]$. SHV-1 is an important plasmid mediated $\beta$-lactamase found in the chromosome of most strains of Klebsiella pneumonia. Its hydrolytic spectrum of activity is similar to that of TEM - 1 , but it shows better activity against ampicillin $[10,11]$. Natural evolution and appearance of mutations has taken place in response to an array of different penicillin derivatives, cephamycins and fourth generation cephalosporins. After identification of SHV-2, the first plasmid-mediated $\beta$-lactamase capable of hydrolyzing extended-spectrum cephalosporins, several point mutations in SHV $\beta$-lactamase have been reported
C Biomed Central

(C) 2011 Rayamajhi et al; licensee BioMed Central Ltd. This is an Open Access article distributed under the terms of the Creative Commons Attribution License (http://creativecommons.org/licenses/by/2.0), which permits unrestricted use, distribution, and reproduction in any medium, provided the original work is properly cited. 
that altered the architecture of the active site of the enzyme [8,12-14]. This modification leads to either an increase in minimum inhibitory concentration (MIC) or broadens the spectrum of the antimicrobial resistance observed. Amino acids from the region around the position 182 to the catalytic triad do not generally tolerate substitution in TEM $\beta$-lactamase and are thought to be necessary for proper core packing and catalytic residue orientation [15,9]. Highly conserved residues on Class A $\beta$-lactamases (Phe 66 and Pro 67) are involved in hydrophobic core packing interactions. Likewise Thr 71 and Lys 73 are important for proper positioning of the catalytic residues Ser 70 and Asn 132 [16,13]. However, the effect of substitutions on amino-acid residues that alter the substrate hydrolyzing property of SHV enzyme is still unknown. The SHV $\beta$-lactamases identified in our study contained a single L138P change compared to wild-type enzyme SHV-1. Since this mutation occurred naturally in SHV-1 $\beta$-lactamases, we speculated that any changes in the substrate affinity must be attributed to this single amino acid substitution. Thus, to gain deeper insight we performed cloning, expression and enzyme kinetics of SHV L138P $\beta$-lactamase. For uniformity and comparative study we cloned a wild type $b l a_{\mathrm{SHV}-1}$ gene from $K$. pneumoniae into the pET 200 cloning and expression vector. This plasmid was used as template for creating SHV-33 and target mutant SHV alleles (bla $a_{\mathrm{SHV}-\mathrm{L} 138 \mathrm{P},} b l a_{\mathrm{SHV}-33}$ (L138P) by site directed mutagenesis. Since SHV-33 has a single amino-acid substitution in SHV-1 and was previously identified in our study, we used these known $\beta$-lactamases as control. The phenotypic and enzyme kinetics results were also verified by a molecular docking simulation experiment.

\section{Methods}

\section{Bacterial strains}

E. coli was isolated from the feces of pigs with mixed clinical signs of digestive and a respiratory disorder was identified by biochemical tests and by VITEK (Vitek system; bioMerieux, Marcy l'Etoile, France). Once identified, the culture was stored in Tryptic Soy Broth (TSB) (Difco Laboratories, Detroit, MI) mixed with 20\% glycerol (Shinyo Pure Chemicals Co. Ltd., Japan) at $-70^{\circ} \mathrm{C}$ until use.

\section{Bacterial strains and antimicrobial tests}

An E. coli isolated from the feces of pigs with mixed clinical signs of digestive and a respiratory disorder was tested with antibiotic susceptibility discs according to the guidelines of the Clinical and Laboratory Standards Institute (CLSI) [17]. The active ingredients of the selected antibiotics were cefotaxime (CTX), ceftazidime (CAZ), cefoxitin (FOX) and ceftiofur (CEF). The isolate was further tested by the double disk diffusion tests using cefotaxime (CTX), ceftazidime (CAZ), cefoxitin (FOX) in combination with amoxicillin/clavulanic acid (AMC) (Becton Dickinson, Germany) and Oxoid Ltd., UK) [17]. The $\mathrm{MIC}_{\mathrm{S}}$ were determined by micro broth dilution method for the cephalosporins that showed complete or decreased inhibition zone diameter in the disk diffusion test. Performance and evaluation of the MIC determinations followed the recommendation of the CLSI [18].

\section{Sequence analysis of the $\beta$-lactamases genes}

Oligonucleotide primers targeting TEM and SHV $\beta$-lactamases and sequencing of the PCR products was performed as described in our previous study [5]. The search for the homologous sequence was conducted in the GenBank database using the Basic Local Alignment Search Tool (BLAST) through the National Center for Biotechnology Information (NCBI) web site (http:// www.ncbi.nlm.nih.gov/BLAST). Nucleotide substitutions were analyzed based on information available in http:// www.lahey.org/studies/webt.htm.

\section{Site directed mutagenesis of bla $\mathrm{SHV}_{\mathrm{H}-1}$ genes}

Wild type bla $a_{\mathrm{SHV}-1}$ gene from $K$. pneumoniae was cloned in pET 200 cloning vector. This plasmid was used as template for generating $b l a_{\mathrm{SHV}(\mathrm{L} 138 \mathrm{P})}, b l a_{\mathrm{SHV}-33}$ (P226S) and bla $a_{\mathrm{SHV}-33(\mathrm{~L} 138 \mathrm{P})}$ genes by site directed mutagenesis following the procedures described by Zheng et. al [8,19]. Description of the primers used in the study are listed in Table 1 . All the PCR-amplified products were evaluated by agarose gel electrophoresis and the band with the expected size was extracted using QIAEX $^{\circledR}$ II gel extraction kit (Qiagen, Hilden, Germany) and further treated with $10 \mathrm{U} D p n \mathrm{I}$ (New England, Hertfordshire, UK) and incubated at $37^{\circ} \mathrm{C}$ for $3 \mathrm{hrs}$. An aliquot of $2 \mu \mathrm{l}$ of this PCR product was transformed into TOPO 10 competent cells and plated on Tryptic Soy Agar (TSA) (Difco Laboratories, Detroit, MI) agar plate containing $100 \mu \mathrm{g} / \mathrm{ml}$ of kanamycin. A total of 3 colonies were selected and their plasmids were extracted using mini-prep. Sequences of all these $\beta$-lactamases were confirmed twice by the nucleotide sequencing using T7 forward and reverse primers.

\section{$\beta$-lactamase expression and Western blot}

The expression of four different recombinant proteins encoding in the pET 200 expression vector carrying bla $_{\mathrm{SHV}-1}, b l a_{\mathrm{SHV}-1(\mathrm{~L} 138 \mathrm{P}),}, \operatorname{la}_{\mathrm{SHV}-33}$ and bla $_{\mathrm{SHV}-33(\mathrm{~L} 138 \mathrm{P})}$ genes was carried out in Rossetta-gami (RG) E. coli cells. The cells pellets harvested by centrifugation were washed with PBS twice, re-suspended in lysis buffer (20 $\mathrm{mM}$ imidazole) overnight at $4^{\circ} \mathrm{C}$ and lysed by sonication. The His Spin Trap (GE Healthcare, Buckinghamshire, UK) were used for elution of the protein by 
Table 1 Primers used for detection of TEM and SHV $\beta$-lactamases and for site directed mutagenesis in this study

\begin{tabular}{|c|c|c|c|c|c|}
\hline Targets & Primer & Sequence $\left(5^{\prime}-3^{\prime}\right)$ & $\begin{array}{l}\text { Product } \\
\text { size(bp) }\end{array}$ & $\begin{array}{l}\text { Annealing } \\
\text { temp }\end{array}$ & $\begin{array}{c}\text { Gene bank } \\
\text { Accession } \\
\text { no. }\end{array}$ \\
\hline TEM & TEM-F TEM-R & TCG GGG AAA TGT GCG TGC TTA ATC AGT GAG GCA CC & 1074 & 62 & AM849806 \\
\hline SHV & SHV-F SHV-R & GCC GGG TTA TTC TTA TIT GTC GC ATG CCG CCG CCA GTC A & 1016 & 62 & EU342351 \\
\hline SHV-M ${ }^{a}$ & SHV-MF SHV-MR & C AAT CTG $\underline{\text { CCG }}$ CTG GCC ACC GTC GGC GGC CAG $\underline{\text { CGG }}$ CAG ATT GGC GGC GCT & & 52 & - \\
\hline $\begin{array}{l}\text { SHV- } \\
33^{\mathrm{b}}\end{array}$ & $\begin{array}{c}\text { SHV-33F SHV- } \\
33 R\end{array}$ & 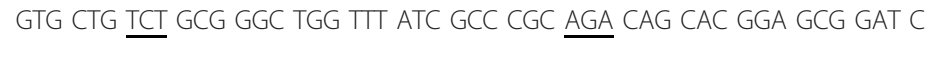 & & 52 & - \\
\hline
\end{tabular}

a:primer used to create the mutation L138P in SHV-1 $\beta$-lactamase identified in this study.

b:primer used to create a single mutation P226S (SHV-33 $\beta$-lactamase).

$500 \mathrm{mM}$ imidazol and protein concentrations of all $\beta$ lactamases were determined by BCA protein assay kit (Pierce, Rockford, IL) with bovine serum albumin as standard [20]. Proteins separated by SDS-PAGE (MiniProtean II, Bio-Rad, Hercules, CA, USA) were transferred to Hybond ECL nitrocellulose membrane (Amersham life Science, Buckinghamshire, UK), and incubated in anti His mouse IgG followed by rabbit anti mouse IgG. Binding was detected using an AP conjugate substrate kit (Bio-Rad) according to the manufacture's instruction.

\section{Enzyme activity assay}

$\beta$-lactamase activity was determined by observing the rate of penicillin and ampicillin hydrolysis at $240 \mathrm{~nm}$ and $235 \mathrm{~nm}$, respectively. Enzyme assay was performed at $25^{\circ} \mathrm{C}$ in $1 \mathrm{mM}$ phosphate buffer (pH 7.0) [12]. Spectrophotometric measurements were made on Analytic Jena AG (winASPECT ${ }^{\circledR}$, spectroanalytical software) using 1.0-cm path length cuvette. The values for $K_{\mathrm{m}}$ and $V_{\max }$ were determined using GraFit 6 (Erithacus Software, UK).

\section{Molecular docking simulation}

The wild-type structure of SHV (pdb code: 1shv) was used as a template for molecular modeling. All molecular modeling simulations were performed by Discovery Studio 2.5 (Accelrys, USA) and CHARMm forcefield and CFF partial charge were used for all simulations. The conformation of L138P position was optimized by the Dreiding minimization and the molecular dynamics by standard dynamics cascade protocol was applied to relax the conformations of the wild-type and L138P mutant with and default parameters except that production steps was 3000 and implicit solvent model was set to Generalized Born method. Among produced structures, the most stable structure with the lowest potential energy was selected as modeled structure for further docking simulation.

The docking simulations of $\beta$-lactamases were conducted by CDOKER module with manually designed penicillin and ampicillin molecules. Because the active site and catalytic residues of SHV and TEM lactamasese are highly conserved, the structure of TEM with bound penicillin G (pdb code: $1 \mathrm{fqg}$ ) was used as a reference structure to identify the initial binding site of penicillin and ampicillin in the wild-type and L138P lactamases. Once docking complexes of lactamases and antibiotics were predicted by CDOCKER module, productive docking structures of the carbonyl carbon of $\beta$-lactam ring of penicillin and ampicllin directly oriented to the $\mathrm{OH}$ group of catalytic S70 of $\beta$-lactamases (for nucleophilic attack of S70) were considered further binding energy calculation (Figure 1). The binding energies of the wildtype and L138P lactamases toward penicillin and ampicillin were calculated using Calculate Binding Energies protocol with default parameters except that ligand minimization were performed to consider the flexibility of residues within binding sites and implicit solvent model was set to Generalized Born method.

\section{Results}

Antimicrobial resistance phenotype and genotype

E. coli 485 exhibited resistance to the commonly used antimicrobial agents on farms. The Disk diffusion test showed reduced inhibition zone diameter to cefotaxime (CTX), ceftazidime(CAZ), ceftiofur (CEF) but not to cefoxitin (FOX). This strain exhibited $>5 \mathrm{~mm}$ increase in inhibition zone diameter of both cefotaxime and ceftazidime in the presence of amoxicillin/clavulanic acid (AMC) in contrast to when the antibiotics were tested alone. RG E. coli cells carrying bla $a_{\mathrm{SHV}-1}$, blaSHV $_{-(\mathrm{L} 138 \mathrm{P})}$, $b l a_{\mathrm{SHV}-33}$ and $b l a_{\mathrm{SHV}-33(\mathrm{~L} 138 \mathrm{P})}$ exhibited variable zone diameter to penicillin and ampicillin in the disk diffusion test. No decrease in zone diameter was noticed for cefotaxime (CTX), ceftazidime(CAZ), ceftiofur (CEF) and cefoxitin (FOX). The MIC values for all E. coli strains are listed in table 2. Genotype analysis of $E$. coli isolate showed TEM and SHV $\beta$-lactamase genes showed $100 \%$ identity to $b l a_{\mathrm{TEM}-20}$ and $b l a_{\mathrm{SHV}-1}$ genes except at position 138 where leucine $(\mathrm{L})$ to proline $(\mathrm{P})$ polymorphism was detected. 


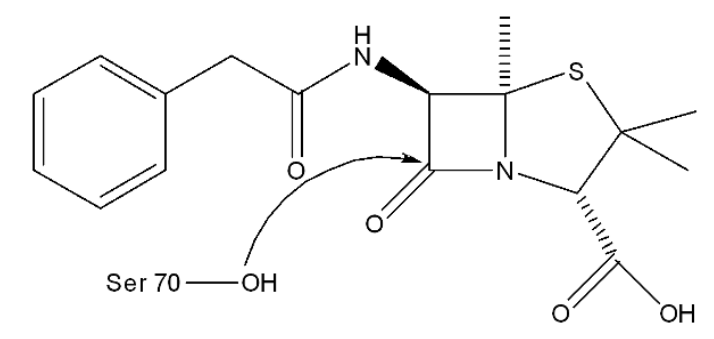

A

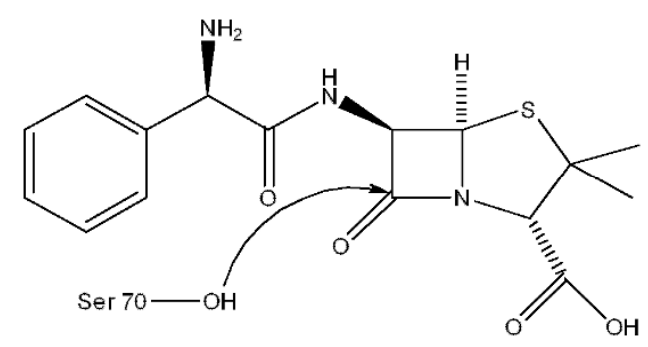

B

Figure 1 Structures of penicillin G (A) and ampicillin (B).

Site directed mutagenesis of bla $\mathrm{SHV}_{\mathrm{H}-1}$ genes

After cloning and confirmation of $b l a_{\mathrm{SHV}-1}$ genes in the pET 200 cloning and expression vector, reverse mutation at single point (L138P) was successfully performed by site directed mutagenesis to generate $b l a_{\mathrm{SHV}-(\mathrm{L} 138 \mathrm{P})}$. Plasmid carrying bla $a_{\mathrm{SHV}-1}$ gene was used to generate another mutation (S226P) that showed complete identity to $b l a_{\mathrm{SHV}-33}$ gene. Sequence analysis also showed that the final site directed mutagenesis on the plasmid carrying $b l a_{\mathrm{SHV}-33}$ gene, gave rise to the $b l a_{\mathrm{SHV}-33(\mathrm{~L} 138 \mathrm{P}) \text {. }}$

Cloning, expression and $\beta$-lactamase activity assay All four pET 200 cloning and expression vectors carrying bla $_{\mathrm{SHV}-1}, b l a_{\mathrm{SHV}-1(\mathrm{~L} 138 \mathrm{P})}, b l a_{\mathrm{SHV}-33}$ and $b l a_{\mathrm{SHV}-33(\mathrm{~L} 138 \mathrm{P})}$ genes expressed in Rossetta-gami E. coli cells. Expressed proteins matched the size of $32.22 \mathrm{kDa}$ in SDS-PAGE and Western blot. Enzyme kinetics showed that SHV $\beta$ lactamases cloned and expressed in this study exhibited variable catalytic activity of penicillin and ampicillin. $K_{\mathrm{m}}$ value for both penicillin ampicillin was lowest for SHV-1 $\beta$-lactamase followed by SHV-33, SHV-33(L138P) and SHV-L138P. The description of the $K_{m}, k_{\text {cat }}$ and $k_{\text {cat }} / K_{m}$ values are given are listed in table 3.

\section{Molecular docking simulation of SHV lactamases}

The structures of the wild-type and L138P mutant were prepared by molecular dynamics. The alpha helix of L138P mutant including 138 position was shorter than that of the wild-type and the orientation of the catalytic residues were slightly changed due to the proline mutation (Figure 2). The productive docking structures with the lowest binding energies predicted by Discovery Studio 2.5 were selected as binding structures of penicillin and ampicillin (Figure 3). The wild-type showed higher binding affinity (lower binding energy) of both penicillin $(16.5 \mathrm{kcal} / \mathrm{mol})$ and ampicillin $(31.2 \mathrm{kcal} / \mathrm{mol})$ than the L138P mutant, confirming that the L138P mutant had poor binding affinity (higher $\left.K_{m}\right)$ of penicillin $(19.4 \mathrm{kcal} /$ $\mathrm{mol})$ and ampicillin $(36.3 \mathrm{kcal} / \mathrm{mol})$ compared to the wild-type. The wild-type and L138P mutant had lower binding energies of penicillin $(16.5$ and $19.4 \mathrm{kcal} / \mathrm{mol}$ respectively) over ampicillin (31.2 and $36.3 \mathrm{kcal} / \mathrm{mol}$ respectively), consistent with experimental results that both $\beta$-lactamases preferred penicillin to ampicillin.

\section{Discussion}

Extensive research on $\beta$-lactam resistance has been carried among the clinical hospital isolates and majority of $\beta$-lactamases reported to date have been derived from clinical isolates of humans. However, recent research has shown the increasing occurrence of $\beta$-lactam

Table 2 Phenotype and genotype of $\beta$-lactamases for the $E$. coli field isolate and mutants included in the study

\begin{tabular}{|c|c|c|c|c|c|c|c|c|}
\hline \multirow[b]{2}{*}{ Strains } & \multicolumn{6}{|c|}{ Inhibition Zone diameter $(\mathrm{mm}) / \mathrm{MICs}(\mathrm{mg} / \mathrm{L})^{\mathrm{a}}$} & \multicolumn{2}{|c|}{$\beta$-lactamases } \\
\hline & AM & PEN & CEF & FOX & CAZ & CTX & SHV & TEM \\
\hline E. coli & $\leq 1 / 640$ & $\leq 1 / 640$ & $8 / 320$ & $15 / 20$ & $11 / 160$ & $12 / 320$ & SHV-1(L138P) & TEM-20 \\
\hline RG E. coli-M1 & $12 / 160$ & $1 / 40$ & - & - & - & - & SHV-1 & \\
\hline RG E. coli-M2 & $28 / 40$ & $14 / 40$ & - & - & - & - & L138P & \\
\hline RG E. coli-M3 & $11 / 160$ & $1 / 160$ & - & - & - & - & P226S & \\
\hline RG E. coli-M4 & $28 / 20$ & $12 / 2$ & - & - & - & - & L138P P226S & \\
\hline
\end{tabular}

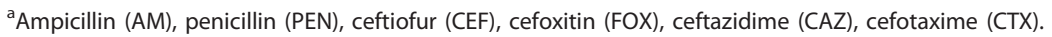


Table 3 Kinetics parameters for penicillin and ampicillin

\begin{tabular}{|c|c|c|c|c|c|c|}
\hline \multirow[b]{2}{*}{ Enzymes } & \multicolumn{3}{|c|}{ penicillin } & \multicolumn{3}{|c|}{ ampicillin } \\
\hline & $\begin{array}{c}K m \\
(\mu \mathrm{M})\end{array}$ & $\begin{array}{l}\text { Kcat } \\
\left(\mathrm{s}^{-1}\right)\end{array}$ & $\begin{array}{l}\text { Kcat } / K m \\
\left(\mu M^{-1} s^{-1}\right)\end{array}$ & $\begin{array}{c}K m \\
(\mu \mathrm{M})\end{array}$ & $\begin{array}{l}\text { Kcat } \\
\left(\mathrm{s}^{-1}\right)\end{array}$ & $\begin{array}{l}\text { Kcat } / K m \\
\left(\mu \mathrm{M}^{-1} \mathrm{~s}^{-1}\right)\end{array}$ \\
\hline SHV-1 & 49 & 1460 & 29.79 & 26 & 5910 & 227.3 \\
\hline SHV-1(L138P) & 76 & 3370 & 4.43 & 87 & 1363 & 15.66 \\
\hline SHV-33 & 59 & 2140 & 36.27 & 16 & 1375 & 85.93 \\
\hline SHV33-L138P & 91 & 2680 & 29.45 & 90 & 1503 & 16.7 \\
\hline
\end{tabular}

resistance in microbes of animal origin, especially in animal derived E. coli and Salmonella, which are related to community acquired infections and food safety $[1,5,21]$. In continuation of our study effort to address some of these issues of antimicrobial resistance in Enterobacteriaceae isolated from farm animals, our study focused on

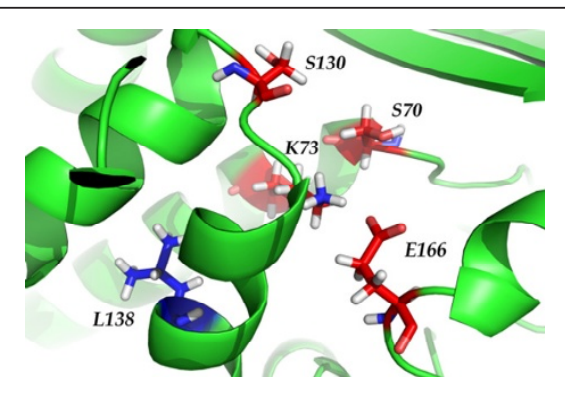

$\mathrm{A}$

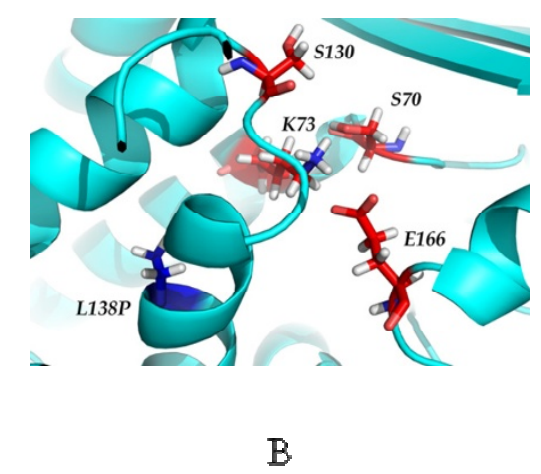

Figure 2 Structure of the wild-type (A) and L138P $\beta$-lactamases (B). The red and blue residues indicate the catalytic residues (S70K73-S130-E166) and mutation site (L138P), respectively. the identification and understanding the dynamics of unique $b l a_{\mathrm{SHV}-\mathrm{L} 138 \mathrm{P}}$ mutation observed in $E$. coli isolated from swine.

Phenotypic antimicrobial tests showed that the E. coli isolate was resistant to the common antimicrobial agents used in farms and also exhibited reduced sensitivity to three indicator cephalosporins included in the study. Genetic analysis showed the presence of both TEM-20 and SHV $\beta$-lactamases that differed from SHV-1 only by a single amino acid substitution leucine to proline at position 138. This mutation was of special interest as SHV $\beta$-lactamses are specially related to $K$. pneumoniae and we wanted to see if this $b l a_{\mathrm{SHV}}$ gene with single amino-acid substitution (L138P) detected in E. coli added to its substrate hydrolyzing activity $[1,2,4,22,23]$.

All the cloned $b l a_{\mathrm{SHV}}$ genes expressed the specific protein bands that were confirmed by SDS-PAGE and Western blot. The size of the expressed SHV $\beta$-lactamases was larger than reported in previous research because of the intact 23 amino acid pro-peptide and His tag [20]. The enzyme kinetics of all the expressed $\beta$-lactamases showed differences in the affinities for penicillin and ampicillin that were included in this experiment (Table 3). The narrow spectrum $\beta$-lactamases SHV-1 and SHV-33 exhibited higher affinity to penicillin and ampicillin respectively, whereas SHV-1 and SHV-33 with only in one amino acid (L138P) mutation exhibited reduced activity for both the substrate used in study. This indicated that leucine at position 138 was important for SHV $\beta$-lactamase and played an important role in hydrolyzing penicillin and ampicilin.

Previous experiments on SHV $\beta$-lactamases have reported three natural mutations at position 69,130 and 187 to be involved in conferring resistance to the inhibitors [11-13]. Proline has stronger stererochemical constraints than any other residues, with only one instead of two variable backbone angles and it lacks the normal amine backbone for hydrogen bonding. This could have the disruptive function to regular secondary structure and decreased the length of $\alpha$-helix and changed the orientation of residues of binding sites. Based on the modeled docking structures of the wild-type and L138P mutant, the wild-type had three hydrogen bonds with penicillin and ampicillin but the L138P mutant had two hydrogen bonds, indicating that these structural changes by L138P mutation may decrease the substrate binding and finally resulted in reduced activity of L138P mutant. This result was supported by higher $K_{m}$ value for penicillin and ampicillin of L138P mutation when inserted in SHV-1 and SHV-33.

\section{Conclusions}

Based on our results we concluded that this mutation caused a drop in hydrolyzing penicillin and ampicillin. 


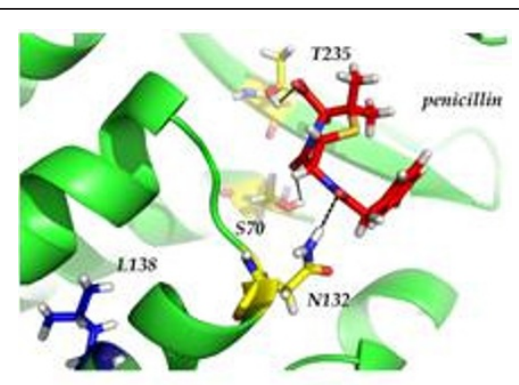

A

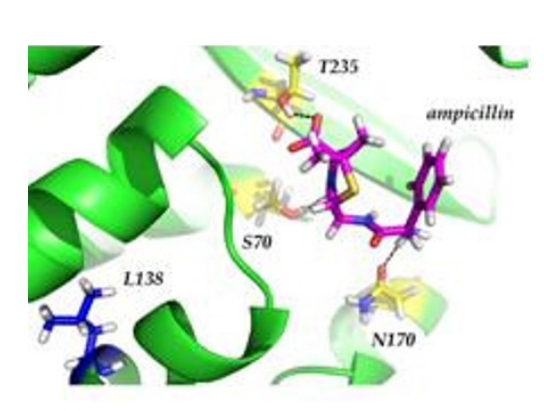

B

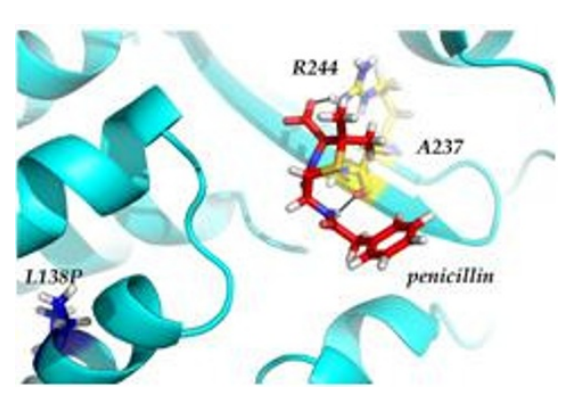

$\mathrm{C}$

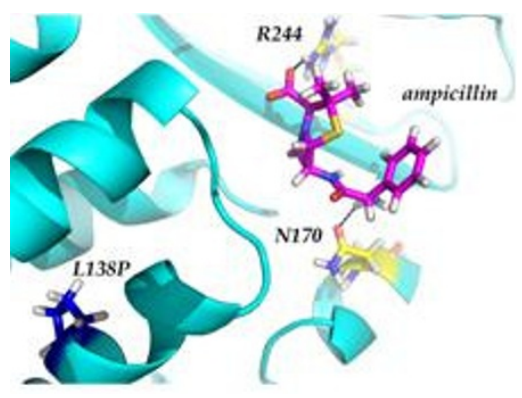

D

Figure 3 Modeled docking structures of $\boldsymbol{\beta}$-lactamases and penicillin and ampicillin. (A) Docking structure of the wild-type and penicillin (B) Docking structure of wild-type and ampicillin (C) Docking structure of L138P mutant and penicillin (D) Docking structure of L138P mutant and ampicillin. The dashed lines indicate hydrogen bonds and the red residues indicate catalytic residues.
Under the selection pressure imposed by the use of these antimicrobials, naturally occurring L138P mutation in the conserved region of bla $a_{\mathrm{SHV}}$ gene was expected to increase substrate hydrolyzing property or widen the substrate spectrum of SHV- $\beta$-lactamases. However, adverse effect of this mutation observed on its substrate hydrolyzing properties may be a way these microbes trigger emergence or acquisition of more effective alternative mechanisms. Our speculation is in line with recent reports on CTX-M and AmpC $\beta$-lactamases that have more frequently been reported than the classical TEM and SHV $\beta$-lactamase from farm and food materials $[1,3,4,7,21]$.

\section{Acknowledgements}

This work was supported by a Korea Research Foundation Grant funded by the Korean Research Foundation (KRF-2006-21-E00011, KRF-2006-005J502901), a BK-21 grant, and a Bio-green 21 grant (20070401-034-009-007-01$00), \mathrm{RDA}$ and the Research Institute for Veterinary Science, Seoul National University, Korea.

\section{Author details}

${ }^{1}$ Department of Infectious Diseases, College of Veterinary Medicine, KRF Zoonotic Disease Priority Research Institute, Brain Korea 21 for Veterinary Science, Seoul National University, Seoul 151-742, S. Korea. ${ }^{2}$ School of Chemical and Biological Engineering, Seoul National University, Seoul 151744 , S. Korea.

\section{Authors' contributions}

NR, SBC and MKS carried out cloning expression and western blot, SP contributed in enzyme kinetics, JCJ did Simulation docking experiment. YJY and HSY provided guidance and helped coordination. All authors have read and approved the final manuscript.

Received: 13 August 2010 Accepted: 4 February 2011

Published: 4 February 2011

\section{References}

1. Bradford PA: Extended-spectrum $\beta$-lactamases in the $21^{\text {st }}$ century: characterization, epidemiology and detection of this important resistance threat. Clin Microbiol Rev 2001, 14:933-51.

2. Chaves J, Ladons MG, Segura C, Coira A, Reig R, Ampurdanés C: SHV-1 $\beta$-lactamses is mainly a chromosomally encoded species-specific enzyme in Klebsiella pneumoniae. Antimicrob Agents Chemother 2001, 45:2856-61.

3. Su LH, Chu C, Cloeckaert A, Chiu CH: An epidemic of plasmids? Dissemination of extended-spectrum cephalosporinases among Salmonella and other Enterobacteriaceae. FEMS Immunol Med Microbial 2008, 52:155-68.

4. Spanu T, Luzzaro F, Perilli M, Amicosante G, Toniolo A, Fadda G, Italian ESBL Study Group: Occurrence of Extended-Spectrum $\beta$-Lactamases in Members of the Family Enterobacteriaceae in Italy: Implications for Resistance to $\beta$-Lactams and Other Antimicrobial Drugs. Antimicrob Agents Chemother 2002, 46:196-202.

5. Rayamajhi N, Kang SG, Lee DY, Kang ML, Lee SI, Park KY, Lee HS, Yoo HS: Characterization of TEM-, SHV- and AmpC-type beta-lactamase from cephalosporin-resistant Enterobacteriaceae isolated from swine. Int $\mathrm{J}$ Food Microbiol 2008, 124:183-7.

6. Lee KY, Hopkins JD, O'Brien TF, Syvanen M: Gly-238-Ser substitution changes the substrate specificity of the SHV class A beta-lactamases. Proteins 1991, 11:45-51.

7. Livermore DM, Canton R, Gniadkowski M, Nordmann P, Rossolini GM, Arlet G, Ayala J, Coque TM, Kern-Zdanowicz I, Luzzaro F, Poirel L, Woodford N: CTX-M:changing the face of ESBLs in Europe. J Antimicrob Chemother 2007, 59:165-74. 
8. Ambler RP, Coulson AF, Frère JM, Ghuysen JM, Joris B, Forsman M, Levesque RC, Tiraby G, Waley SG: A standard numbering scheme for the class A beta-lactamases. Biochem J 1991, 276:269-70.

9. Orencia MC, Yoon JS, Ness JE, Stemmer WP, Stevens RC: Predicting the emergence of antibiotic resistance by directed evolution and structural analysis. Nat Struct Biol 2001, 8:238-42.

10. Gutmann L, Ferré B, Goldstein FW, Rizk N, Pinto-Schuster E, Acar JF, Collatz E: SHV-5, a novel SHV-type $\beta$-lactamase that hydrolyzes broadspectrum cephalosporins and monobactams. Antimicrob Agents Chemother 1989, 33:951-6.

11. Mendonca N, Manageiro V, Bonnet R, Canica M: Biochemical characterization of SHV-55, an extended-Spectrum class A $\beta$-Lactamase from Klebsiella pneumoniae. Antimicrob Agents Chemother 2008, 52:1897-8.

12. Huletsky A, Knox JR, Levesque RC: Role of Ser- 238 and Lys-240 in the hydrolysis of third-generation cephalosporins by SHV-type $\beta$-lactamases probed by site-directed mutagenesis and three-dimensional modeling. J Biol Chem 1993, 15:3690-97.

13. Kalp M, Bethel CR, Bonomo RA, Carey PR: Why the extended-spectrum beta-lactamases SHV-2 and SHV-5 are "hypersusceptible" to mechanismbased inhibitors. Biochemistry 2009, 48:9912-20.

14. Matagne A, Lamotte-Brasseur J, Frere JM: Catalytic properties of class A ß-lactamases: efficiency and diversity. Biochem J 1998, 330:581-98.

15. Barlow M, Hall BG: Predicting evolutionary potential: in vitro evolution accurately reproduces natural evolution of the tem beta-lactamase. Genetics 2002, 160:823-32.

16. Reynolds KA, Thomson JM, Corbett KD, Bethel CR, Berger JM, Kirsch JF, Bonomo RA, Handel TM: Structural and Computational Characterization of the SHV-1 $\beta$-Lactamase- $\beta$-Lactamase inhibitor protein interface. J Biol Chem 2006, 281:5-532674.

17. Clinical and Laboratory Standards Institute (CLSI): Performance standards for antimicrobial susceptibility testing; $15^{\text {th }}$ informational supplement. M100-S15. Clinical and Laboratory Standards Institute, Wayne, Pa; 2006.

18. Clinical and Laboratory Standards Institute (CLSI): Performance standards for antimicrobial susceptibility testing; $19^{\text {th }}$ informational supplement. M100-S19. Clinical and Laboratory Standards Institute, Wayne, Pa; 2009.

19. Zheng L, Baumann U, Reymond JL: An efficient one-step site-directed and site saturation mutagenesis protocol. Nucleic Acid Res 2004, 32(14).

20. Mendonca N, Manageiro V, Robin F, Salgado MJ, Ferreira E, Caniça M, Bonnet R: The Lys234Arg substitution in the enzyme SHV-72 is a determinant for resistance to clavulanic acid inhibition. Antimicrob Agents Chemother 2008, 52:1806-11.

21. Li X-Z, Mehrotra M, Ghimire S, Adewoye L: $\beta$-Lactam resistance and $\beta$ lactamases in bacteria of animal origin. Vet Microbiol 2007, 121:197-214

22. Haggman S, Lofdahl S, Burman LG: An allelic variants of the chromosomal gene for class A $\beta$-lactamase K2, specific for Klebsiella pnemoniae, is the ancestor of SHV-1. Antimicrob Agents Chemother 1997, 41:2705-09.

23. Nicolas MH, Jarlier V, Honore N, Philippon A, Cole ST: Molecular characterization of the gene encoding SHV-3 $\beta$-lactamase responsible for transferable cefotaxime resistance in clinical isolates of Klebsiella pneumoniae. Antimicrob Agents Chemother 1989, 33:2096-100.

doi:10.1186/1471-2180-11-29

Cite this article as: Rayamajhi et al: Enzymatic analysis of the effect of naturally occurring Leu138Pro mutation identified in SHV $\beta$-lactamase on hydrolysis of penicillin and ampicillin. BMC Microbiology 2011 11:29.

\section{Submit your next manuscript to BioMed Central and take full advantage of:}

- Convenient online submission

- Thorough peer review

- No space constraints or color figure charges

- Immediate publication on acceptance

- Inclusion in PubMed, CAS, Scopus and Google Scholar

- Research which is freely available for redistribution

Submit your manuscript at www.biomedcentral.com/submit 